AKÜ FEMÜBID 17 (2017) 015801 (239-246)

DOI: $10.5578 / \mathrm{fmbd} .51762$

AKU J. Sci. Eng. 17 (2017) 015801 (239-246)

Araştırma Makalesi / Research Article

Kaza Oranları Hesaplamalarıyla İş Kazası Analizi

\author{
Ali Ekrem Arıtan ${ }^{1}$, Melike Ataman ${ }^{1}$ \\ ${ }^{1}$ Afyon Kocatepe Üniversitesi, Mühendislik Fakültesi, Maden Mühendisliği Bölümü, Afyonkarahisar. \\ e-posta: aritan@aku.edu.tr
}

Geliş Tarihi: 11.11.2016 ; Kabul Tarihi:25.03.2017

Özet

Ülkemizde son yıllarda meydana gelen kazalar, iş sağlığı ve güvenliğinin önemini yeniden gündeme taşımaktadır. Yaşanılan iş kazalarının nedenleri analiz edilerek bu kazaların azaltılması gerekmektedir. Madencilik sektöründe yeraltı maden işletmelerinde olduğu gibi, açık maden işletmelerinde de iş kazaları yaşanmaktadır. Bu çalışmada ETi Maden, Kırka Bor Açık İşletmesinde

Anahtar kelimeler Kaza Oranları; İş Kazası; İ̧ Sağlığı ve Güvenliği; Madencilik
2008-2014 yılları arasında meydana gelen iş kazaları incelenmiştir. İşletmede meydana gelen kazalar; kaza nedeni, kazanın aylara ve yıllara göre dağılımı, yaralanan uzuv ve tecrübeye göre değerlendirilmiştir. İncelemeler sonucunda işletmede en sık karşılaşılan kazaların sonuçlarının; yanma, sıkışma, çarpma, burkulma olduğu tespit edilmiştir. Gövde, el ve ayağın en sık yaralanan uzuvlar olduğu görülmüştür. İşçilerin çalışma yılları ile yaralanan uzuvlarının arasındaki ilişkiler belirlenmiştir. Kazalar ay ve yıllara göre incelenip, grafikler üzerinde yorumlanmıştır. Yapılan çalışmalar ve işletmeden alınan bilgilere göre kaza sıklık, kaza ağırlık ve kaza olabilirlik oranları hesaplanmıştır.

\title{
Work Accident Analysis with Accident Rates Calculations
}

Keywords

Accident Rates; Work Accident;

Occupational Health and Safety; Mining
Abstract

Accidents occurred in recent years, have been placed as recurrence of occupational health and safety importance on our national agenda. Causes of recent work accidents are analyzed due to necessity to reduce the number of these accidents. For mining sector work-related accidents occur not only in underground mine operations but also experienced in open pit sites. Workrelated accidents that occurred between the years 2008-2014 in Kırka Bor Eti Mine Open Pit operations were comparatively analyzed. The accidents evaluated according to incident reason, monthly and yearly distribution, damaged limb or organ and injured worker experience. As outcome of the survey the most common results of accidents in operations are defined as burning, compression, impact, sprains. The most frequently injured limbs were determined as torso, hands and feet. The relationship between the injured limbs and workers experience in years are correlated. Accidents examined in intervals of months and years and reviewed in form of charts. Finally, accident incidence, severity and possibility rates are calculated according to received data from the work place and our observance.

(C) Afyon Kocatepe Üniversitesi 


\section{Giriş}

Insan Hakları Evrensel Bildirgesinde de belirtildiği üzere, insanoğlunun başta gelen haklarından en önemlisi yaşam hakkıdır. Çünkü insan, sırf insan olması nedeniyle doğuştan gelen yaşama hakkına sahip olmaktadır. Yaşam hakkı, insanın vücut ve psikolojik bütünlüğünü koruyabilmesi, bu durumu devam ettirebilmesi ve varlığını dışarıdan gelen etkilerden koruyabilmesi şeklinde tanımlanabilir (Özalp ve Özalp, 2014; Er, 2011). Bu anlamda bireyin bedensel ve ruhsal bütünlük içinde yaşamını sürdürmesi insanın hukuki varlığının en önemli öğelerini oluşturmaktadır. Yaşam hakkı insan haklarının temelini ve en önemli hakkı ifade etmektedir. Diğer tüm hakların varlığı ve kullanımı yaşam hakkına bağlıdır (Kılkış, 2014). Gelişen dünya, ilerlemesini teknik ve sanayi atılımlarda artan hıza borçlu olduğu toplumsal refaha ulaşmasının yanı sıra insan hayatı ve çevre için tehlikeleri de beraberinde getirmekte olup ülkemiz de bu durumdan muaf değildir (Vergragt, 2006).

Günümüzün iş kazaları ve meslek hastalıklarına sebep olan en büyük gerekçe, üretim süreçlerinin artan karmaşıklaşmasının yoğun makineleşmenin ve robotlaşmanın yanı sıra çok yüksek sağ ıı riski içeren kimyasal kullanımıdır (WHO, 1995). Artık iş sağlığı kavramı; işçilerin işyeri ortamı ve çalışma koşulları sebebiyle rahatsızlıklarını giderme olarak değil, baştan sona tüm tesisin, hammaddeden ürüne kadar geçen süreçlerin çalışanları da kapsayacak şekilde sürdürülebilir iyiliğini gözetecek şekilde geliştirilmektedir (Int Kyn. 1).

Arama, üretim safhalarında ve sonrasındaki cevher hazırlama evrelerinde farklı riskler barındıran madencilik sektörü, risklerin önlenememesi sonucunda en tehlikeli iş kollarından birisi olmuştur (Güyagüler ve diğ., 1993).

Bu çalışmada, Ülkemizde önemli yer tutan ve örnek iş sağlığı ve güvenliği çalışmaları yapan Eti Maden Kırka Bor İşletmesinin 2008-2014 yılları arasında meydana gelen iş kazaları incelenmiş olup, elde edilen veriler, aylara, yıllara, vardiya saatlerine, yaralanma sebeplerine ve kazaya uğrayan uzuvlara göre yorumlanmıştır. İşletmede meydana gelen kazaların; kaza sıklık, kaza ağırlık ve kaza olabilirlik oranları hesaplanmıştır. Böylece kazaların sebepleri ayrıntılı bir şekilde incelenmiştir.

\section{Tanımlar}

\section{1. İs sağlığı}

Meslek ayırt etmeksizin, çalışanların fiziksel, psikolojik ve çevresel durumlarını en üst seviyeye ulaştırmaya, sürdürmeye ve çalışanların çalıştıkları şartlar-ortamlar yüzünden sağlıklarının bozulmasını önlemeyi hedefleyen, tehlikelerden korumayı, bedensel ve ruhsal durumlarına en uygun çalışma ortamına yerleştirmeyi ve sürdürmeyi amaçlayan bilim dalıdır. Ayrıca iş sağlığı olgusu, işin çalışana, çalışanlarında işe uyumlarını sağlamayı amaç edinir (Topuzoğlu ve Orhun, 1993; Erkan, 1984; WHO, 1950).

\section{2. İ̧ güvenliği}

Güvenlik; kişinin bedensel ve psikolojik sağlığının korunmasıdır. İ̧̧ güvenliği ise; iş ortamında meydana gelen tehlikelerden korunmak yoluyla bu elverişsiz koşullardan korunarak, sağlıklı ve güvenli çalışma şartları oluşmasını sağlamak için yapılan bilimsel çalışmalardır (Ceylan, 2011). Ayrıca OHSAS 18001'de güvenlik sadece çalışanın değil, işletme ve üretiminde koruma altına alınması şeklinde tanımlanmıştır (OHSAS 18001, 2007). 


\section{3. İ̧ kazası}

Kaza, beklenmedik bir anda ortaya çıkan ve maddi-manevi zarar veren olay olarak tanımlanmaktadır. Kazaların çoğu karmaşık nedenler içermektedir ve birden fazla nedenin birleşmesi sonucu meydana gelmektedir. İ̧̧ kazası ise işyerinde oluşan planlanmamış, ölümle sonuçlanan veya vücut bütünlüğünü ruhen ya da bedenen engelli hâle getiren olaydır (6331, 2012; Bilir, 2004). İş kazası, çalışanın yaptığı işin özelliğinden dolayı ve genellikle inmaller sonucu meydana gelmektedir.

\section{Materyal ve Metot}

\subsection{Materyal}

Kırka bor tesislerin kurulmasına 1970 yılında başlanmıştır (Arıbaş, 2015). Şuan Kırka Bor İşletme Müdürlüğü bünyesinde dört adet boraks pentahidrat (Etibor-48) üretim tesisi bulunmaktadır. Yapılan iyileştirme çalışmaları sonucunda kapasiteleri arttırılarak, üretim kapasitesi $1.10^{6}$ ton/yıl olmuştur (Şekil 1) (Çetiner, 2014).

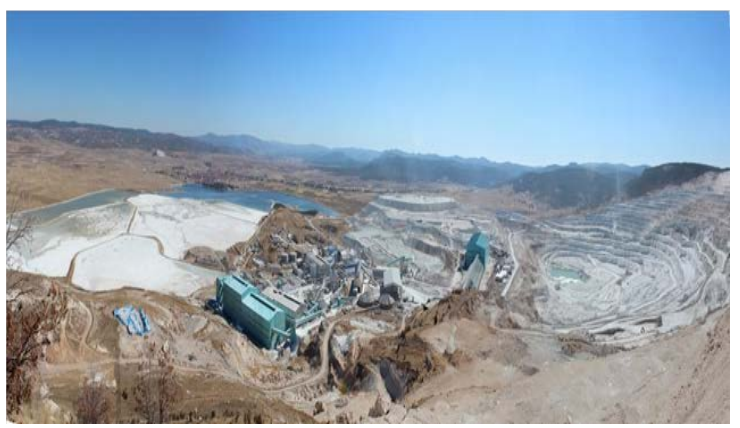

Şekil 1. Ana üretim bölgeleri, açık ocak, fabrikalar, atık sahaları

\subsection{Metot}

Eti Maden Kırka Açık İ̧̧letmesinin, iş kazaları üzerine yetkili birimi olan İş Sağlığı Güvenliği Şube Müdürlüğünce hazırlanan raporlar incelenmiştir. Kazaların aylık ve yıllık dağılımları ile bunun yanında kazaların hangi bölgelerde dağılım gösterdikleri, iş kazalarının dağılımları incelenerek grafiksel olarak gösterilmiştir. Kaza kayıt defterinde yapılan çalışmalar sonucunda, kazalanmaların sebep sonuç ilişkisi ve oluş şekli incelenmiş ve kazalanmaların kaynağı (insan veya tesis) değerlendirilmiştir.

Kaza istatistikleri hesaplanırken, meslek hastalığı vakaları hesaplama dışında tutulmuştur. Karşılaştırmalı ölçüm değerleri dikkate alınarak kullanılan sayısal değerler arasındaki farklılıklar anlamlı hale getirilmiştir. Dikkate alınan ölçüm değerleri; olabilirlik, ağırık ve sıklık oranlarıdır (Balcı ve diğ., 1998).

\subsubsection{Kaza sıklık oranı (KSO) hesaplaması}

İngiltere Sağlık ve Güvenlik İdaresi (HSE)'nin 1999 yılında hazırladığı terimler sözlüğünde; kaza sıklık oranı hesaplaması, bir çalışma yılı içerisinde oluşan iş kazalarında ölümlü ve/veya ölüm gerçekleşmeyen yaralanmaların toplam sayısının, bu çalışma yılı içerisinde inceleme yapılan çalışanların çalışma saatlerinin toplamına bölünmesiyle elde edilen değerin $1.10^{6}$ katsayısıyla çarpılmasıyla hesaplanır (Balcı ve diğ., 1998).

KSO $=$ (Toplam Kaza Sayısı / Toplam çalışma saat sayısı) $\times 1.10^{6}$

\subsubsection{Kaza ağırlık oranı (KAO) hesaplaması}

İngiltere Sağlık ve Güvenlik İdaresi (HSE)'nin 1999 yılında hazırladığı terimler sözlüğünde; bir çalışma yılı içerisinde oluşan iş kazalarında ölümlü ve/veya ölümlü olmayan işyeri yaralanmalardan dolayı oluşan kayıp gün sayısının toplamının, aynı çalışma yılı içerisinde inceleme yapılan çalışanların çalışma saatlerinin toplamına bölünmesiyle elde edilen değerin $1.10^{3}$ katsayısıyla çarpılmasıyla bulunur. Kaza ağırlık oranı hesaplaması 
sırasında, sürekli iş göremezlik durumu veya ölümlü iş kazası varsa, kazalar sonucu oluşan toplam kayıp gün sayısına, her bir ölümlü veya iş göremezlik olayı için ayrı ayrı 7500 gün eklenmesi gerekmektedir (Balcı ve diğ., 1998).

$\mathrm{KAO}=($ Kazalar sonucu oluşan toplam kayıp gün sayısı / Toplam çalışma saat sayısı) $\times 1.10^{3}$

\subsubsection{Kaza olabilirlik oranı (KOO) hesaplaması}

İngiltere Sağlık ve Güvenlik İdaresi (HSE)'nin (1999) yine aynı çalışmasında verilen tanımlamaya göre; bir çalışma yılı içerisinde oluşan iş kazalarında ölümlü ve/veya ölümlü olmayan işyeri yaralanmaların toplam sayısının, aynı çalışma yılı içerisinde, inceleme yapılan çalışanların, çalışma saatlerinin toplamına bölünmesiyle elde edilen değerin $1.10^{5}$ katsayısıyla çarpılmasıyla hesaplanır (Balcı ve diğ., 1998).

$\mathrm{KOO}=$ (Mesleki yaralanmaların toplam sayısı $/$ Referans gruptaki işçi sayısı) $\times 1.10^{5}$

\section{BULGULAR}

\subsection{4 yılı iş kazaları analizi}

2014 yılında aylara göre iş kazaları dağılımı 1 ile 9 kişi arasında değişmektedir. İş kazası sayılarında, Eylül ayındaki düşüş dışında büyük bir farklılık görülmemektedir (Şekil 2).

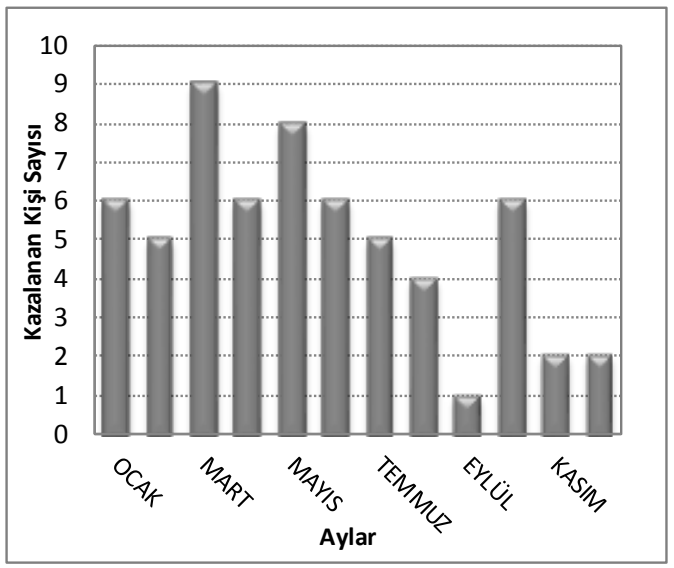

Şekil 2. 2014 Yılı iş kazaları aylara göre dağılımı

\subsection{4 yılı iş kazaları yıllık tecrübeye göre dağııımı}

Çalışanların iş kazası geçirmelerinde hizmet yılları önemli bir parametredir. Meydana gelen iş kazalarının büyük bir çoğunluğu yeni işe başlayan acemi işçi grubuna giren çalışanlarda görülmektedir. Yeni işe başlayan iş̧̧ilerin birçok sebepten kazaya davet çıkardıkları görülmektedir. Deneyimsizlik, yeterli eğitimin aldırımamış olması ve tecrübesiz çalışanların mesleki yeterliliğinin olmaması bu durumun başlıca nedenleri arasındadır. Yine yapılan çalışmalarda görülmüştür ki en fazla kaza geçiren ikinci grup deneyimli sayılacak on yıldan fazla hizmeti bulunan çalışanlardır. Bu gruptaki çalışanların iş kazası geçirmelerine yol açacak nedenlere bakıldığında aşırı güven, zamanla oluşan mesleki körlük ve gelenekselleşmiş çalışma alışkanlıkları öne çıkmaktadır.

Grafikteki verilerden görüldüğü üzere $0-5$ yıl tecrübeli işçiler daha fazla kazaya uğramaktadırlar (Şekil 3). 21-25 yıl tecrübeli işçiler ise daha az kaza geçirmektedirler.

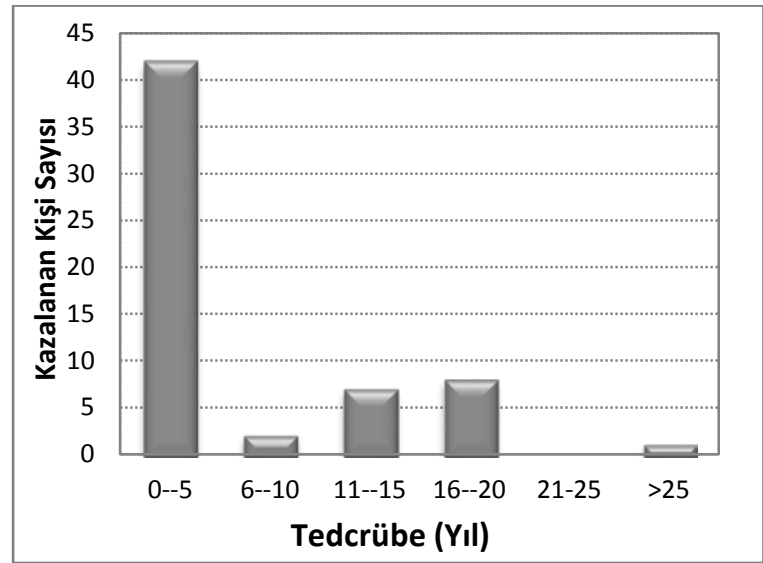

Şekil 3. 2014 yılı iş kazaları yıllık tecrübeye göre dağılımı 


\subsection{4 yılı vardiya saatlerine göre iş kazalar}

Eti Maden Kırka Bor açık işletmesinde haftada 7 gün ve günde 3 vardiya çalışımaktadır. Şekil 4'te, işletmede gerçekleşen kazaların vardiyalara göre dağılımı görülmektedir. 2014 yılında toplam 60 adet iş kazası meydana gelmiştir. $\mathrm{Bu}$ iş kazalarının 33 tanesi 1. vardiyada (08.00-16.00) meydana gelmiştir. Benzer şekilde 2. vardiyada (16.00-00.00), 15 iş kazası 3. vardiyada (00.00-08.00), 12 kaza meydana gelmiştir.

Kaza dağııımlarının nedenleri araştırıldığında 1. ve 2. vardiyada iş yoğunluğunun daha fazla olması ve tüm bakım-onarım işlerinin bu vardiyalarda yapılmasında kaynaklanabileceği sonucuna varılmıştır (Şekil 4).

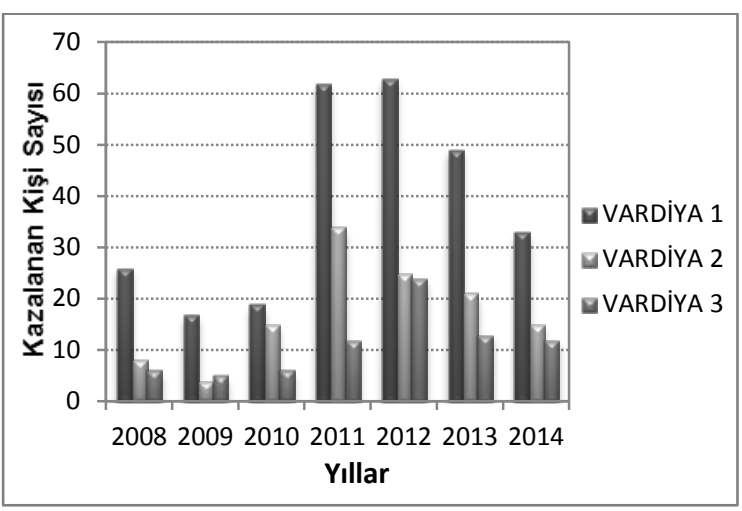

Şekil 4. 2014 yılı vardiya saatlerine göre iş kazaları

\subsection{4 yılı iş kazaları nedenleri}

İsletmede meydana gelen iş kazalarının nedenleri çeşitli sınıflara ayrılmaktadır. 2014 yılı kaza nedenlerine bakıldığı zaman 25 iş kazasının yanmadan kaynaklandığı görülmektedir (sıcak su, çözelti, buhar gibi). Bunun nedeni bor cevherinin çözeltiye geçirilmesi işlemi için prosesin belli bir sıcaklıkta tutulması zorunluluğundandır (Şekil 5).

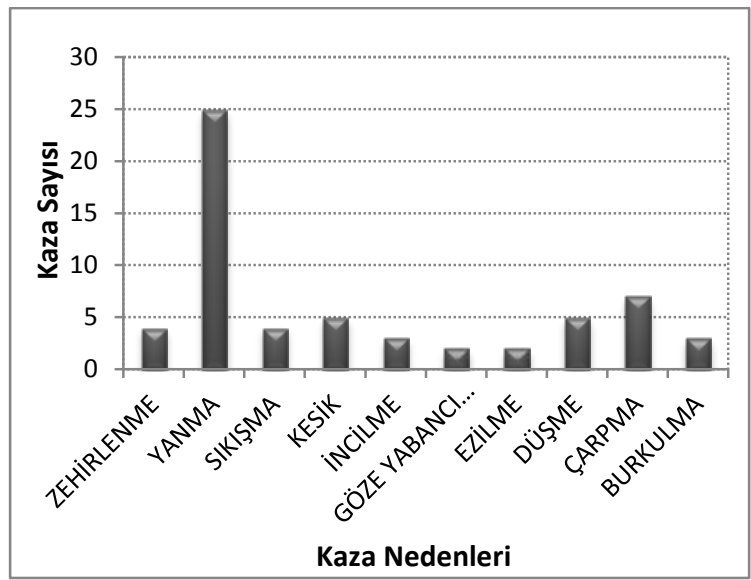

Şekil 5. 2014 yılı kaza nedenleri

\section{5. $2008-2014$ yılları arası iş kazaları}

İşletmenin 7 yıllık iş kazaları verileri incelendiğinde 2008-2014 yılları arasında 469 adet iş kazası meydana gelmiştir. İ̧ kazaları yıllara bağlı olarak detaylı bir şekilde incelendiğinde 2010 yılından sonra ani bir artış yaşandığı görülmektedir (Şekil 6). 2011 yılında yeni tesisler üretime geçmiş ve bu tesislerde çalıştırılmak üzere 250 yeni çalışan istihdam edilmiştir. Dolayısıyla tecrübesiz işçi sayısının artması kaza sayısını da artırmıştır.

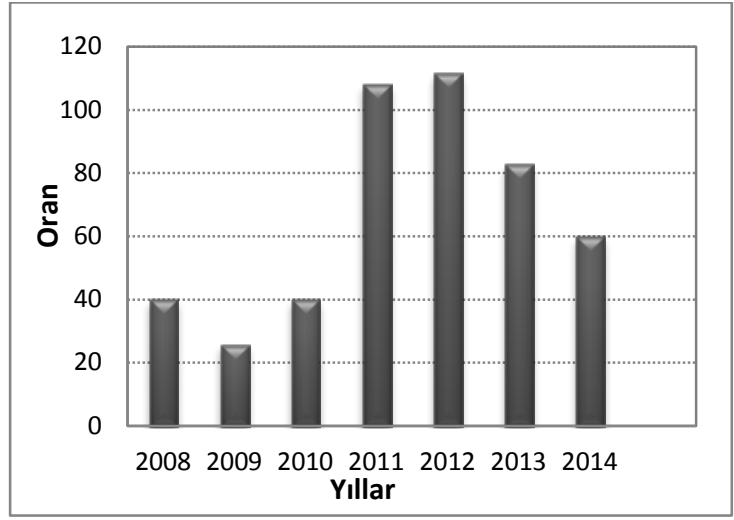

Şekil 6. 2008-2014 yılları arası iş kazaları

\subsection{4 yılı yararlanan uzuvlara göre iş kazaları}

Meydana gelen iş kazaları sonucunda yaralanan uzuvlar Şekil 7'deki gibidir. Beden gücüyle 
çalışılması nedeniyle en fazla gövde, el-kol, ayak uzuvlarında kazalar oluşmaktadır.

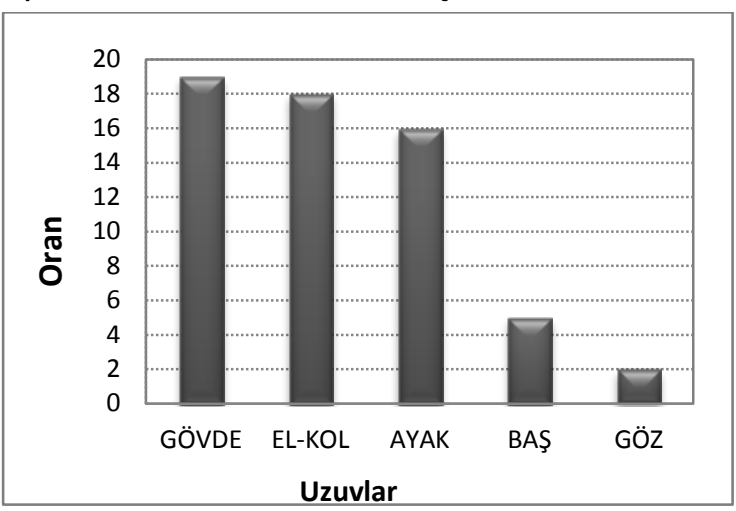

Şekil 7. 2014 yılı yaralanan uzuvlara göre iş kazaları

\section{Hesaplamalar}

\subsection{8-2014 yılları arası kaza sıklık oranının hesaplanması}

Kaza sıklık oranlarının hesaplanmasında kullanılan, 2008-2014 yılları arası iş kazası, kayıp iş günü ve toplam işçi sayıları ve bu rakamlara göre hesaplanan kaza sıklık oranları Tablo 1'de verilmiştir.

Tablo 1. Veriler ve Sonuçlar

\begin{tabular}{lllllll}
\hline Yıllar & $\begin{array}{l}\text { İş } \\
\text { Kazası }\end{array}$ & $\begin{array}{l}\text { Kayıs } \\
\text { Sayısı }\end{array}$ & $\begin{array}{l}\text { Toplam } \\
\text { İşçi }\end{array}$ & $\begin{array}{l}\text { Kaza } \\
\text { Saklık }\end{array}$ & $\begin{array}{l}\text { Kaza } \\
\text { Ağırlık }\end{array}$ & $\begin{array}{l}\text { Kaza } \\
\text { Olabilirlik }\end{array}$ \\
\hline $\mathbf{2 0 0 8}$ & 40 & 439 & 678 & 27,78 & 0,29 & 5,9 \\
$\mathbf{2 0 0 9}$ & 26 & 202 & 646 & 19,77 & 0,14 & 4,02 \\
$\mathbf{2 0 1 0}$ & 40 & 480 & 902 & 21,21 & 0,24 & 4.34 \\
$\mathbf{2 0 1 1}$ & 108 & 932 & 864 & 63,15 & 4,34 & 12.5 \\
$\mathbf{2 0 1 2}$ & 112 & 1020 & 886 & 62,96 & 0,51 & 12,64 \\
$\mathbf{2 0 1 3}$ & 83 & 917 & 974 & 42,18 & 0,42 & 8,5 \\
$\mathbf{2 0 1 4}$ & 60 & 758 & 1048 & 26,32 & 0,32 & 5,7 \\
\hline
\end{tabular}

Kaza sıklık oranının, yıl içerisinde meydana gelen iş kazalarıyla doğru orantılı olduğu görülmektedir (Şekil 8). 2011 ve 2012 yıllarında meydana gelen iş kazalarının fazla olması kaza sıklık oranının da diğer yıllara göre fazla çıkmasına neden olmuştur.

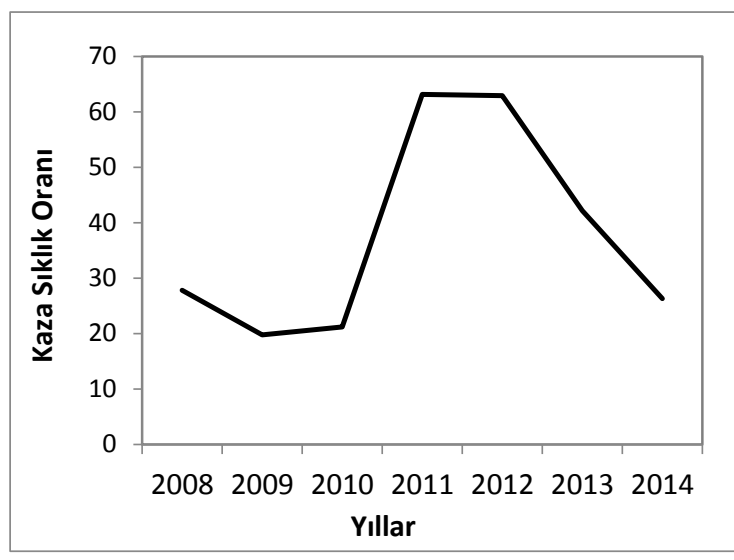

Şekil 8. 2008-2014 yılları arası kaza sıklık oranları

\subsection{8-2014 yılları arası kaza ağırlık oranı} hesaplaması

Kaza ağırlık oranı yıl içerisinde meydana gelen kazalanmalardan kaynaklanan kayıp iş günleri ile doğru orantılı olduğu görülmektedir (Tablo 1, Şekil 9). 2011 yılında meydana gelen ölümlü bir kaza nedeniyle önemli bir artış görülmektedir.

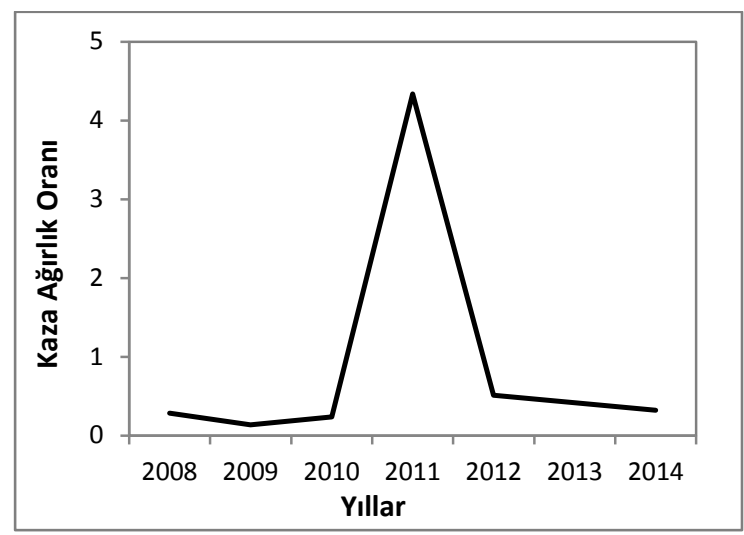

Şekil 9. 2008-2014 yılları arası kaza ağırlık oranları

\subsection{8-2014 yılları arası kaza olabilirlik oranının hesaplanması}

Kaza olabilirlik oranının yıl içerisinde meydana gelen iş kazalarıyla doğru orantılı olduğu görülmektedir (Tablo 1, Şekil 10). 2009 yılında meydana gelen iş kazalarının ve çalışan 
sayısının az olması kaza olabilirlik oranının da diğer yıllara göre az olmasına neden olmuştur.

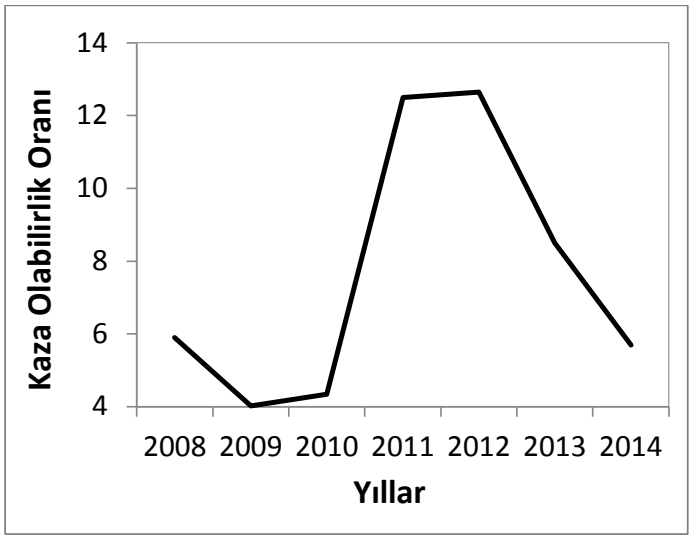

Şekil 10. 2008-2014 yılları arası kaza olabilirlik oranları

\section{Tartışma ve Sonuç}

Bu çalışmada, Eti Maden Kırka Bor Açık İşletmesinde 2008-2014 yılları arasında meydana gelen iş kazaları incelenmiştir. Bu kazaların; önlenebilir kazalar olduğu, diğer sektörlerde olduğu gibi çalışanların eğitim eksikliği ve ihmallerinden kaynaklandığı görülmüştür. Kazalanmaların büyük bir kısmı kişisel hatalar olarak değerlendirilebilir ve müessesenin iş sağlığı ve güvenliği konusundaki eksikliklerinin kaza sebeplerinde çok küçük bir paya sahip olduğu görülebilir. İşletmede, 20112012 yılları arasında iş kazalarında artış görülmüştür. Bu artışa, 2011 yılında işe başlayan 250 çalışanın işi öğrenme sürecinde dikkatsiz davranışlarının sebep olduğu sonucuna varılmıştır. Çalışanların iki yıl içerisinde zamanla tecrübe kazanmaları, denetimlerin arttırılması, kişisel koruyucu donanımları düzenli ve doğru kullanmaları, iş güvenliği bilincinin artması, iş kazalarının azalmasında büyük bir etken olmuştur. İşletme, kazalanmaların eğitim ile çözülebileceğini görmüş, bunun sonucunda çalışanların bilinç seviyelerini artırmak için; iş güvenliği ve mesleki içi eğitimlerini belirli periyotlarda tekrarlamaktadır. Böylece hem psikolojik destek hem de iş güvenliği konusunda bir kültür oluşturulmaktadır.

\section{Teşekkür}

Bu çalışma Eti Maden Kırka Bor Açık İşletmesinden alınan verilerle hazırlanmıştır. Bu verileri almamızda kolaylık sağlayan Kırka Bor İşletme Müdürlüğüne ve Kırka Bor İşletme Müdürlüğü Genel Hizmetler Sorumlusu Neyyir Arıbaş beye teşekkür ederiz.

\section{Kaynaklar}

Arıbaş, N., 2015. Kişisel Görüşme, Eti Maden Kırka Bor İşletmesi Faaliyet Raporu 2014-2015 Yılı, Eskişehir.

Balcı, B., Balcı, Ö., Taçkın, E. ve Yerden, E. A., 2013. İş Kazalarında Mali Kayıplar, İstanbul Sosyal Bilimler Dergisi, 72-74.

Bilir, N., 2004. İş Sağlığı ve Güvenliği, Ankara, Hacettepe Üniversitesi Yayınları, 247-262.

Ceylan, H., 2011. Türkiye'deki İş Kazalarının Genel Görünümü ve Gelişmiş Ülkelerle Kıyaslanması, International Journal of Engineering Research and Development, 3(2), 23.

Çetiner, C., 2014. Kırka Bor İşletme Müdürlüğü İş Kazası Analizi, Lisans Tezi, Eskişehir Osmangazi Üniversitesi, Eskişehir, 23.

Er, Ü., 2011. Sağlıkta Dönüşümün Aracı Genel Sağlık Sigortası, Yüksek Lisans Tezi, Ankara Üniversitesi Sosyal Bilimler Enstitüsü, Ankara, 428.

Erkan, N., 1984 Çalışma Hayatında Fizyolojik Stresler ve Ergonomi, 2. Ulusal Ergonomi Kongresi, MPM Yayını, Ankara, 30-31.

Güyagüler, T., Bozkurt, R. ve Önder, Ü.Y., 1993. Kömür Madenciliğinde İş Kazalarının İstatistiksel ve Ekonomik Analizi, 13. Madencilik Kongresi Bildiriler Kitabı, İstanbul, 102-113.

HSE, 1999. Glossary of HSE Terms, LOGP, Londra, 14 
Kılkış, Ş., 2014. İş Sağlığı ve Güvenliği, Dora BasımYayın Ltd. Şti, Bursa, 215.

OHSAS, 18001, 2007, Occupational Health and Safety Management Systems, British Standarts Institute.

Özalp, T. ve Özalp, F., 2014. Hekimin Cezai Sorumluluğu, Adalet Yayınevi, Ankara, 448.

Topuzoğlu, i. ve Orhun, H., 1993. Türk Tabipleri Birliği, İş Hekimliği Ders Notları, Türk Tabipleri Birliği Yayını, Üçüncü Basım, Maya Matbaacılık, Ankara, 3.

Vergragt, P. J., 2006. How Technology Could Contribute to a Sustainable World. Great Transition Initiative Paper Series, 1-29.

WHO, 1950. Annual Report Of The Director -General To The World Health Assembly And To The United Nations, WHO Publications, 25.

WHO, 1995. Global Strategy in Occupational Health for All: The Way to Health at Work, WHO Publications, 57-59.

6331 Sayılı Kanun, 2012. İş Sağlığı ve Güvenliği Kanunu, 28339 Sayılı Resmi Gazete, Ankara.

\section{Internet kaynakları}

1- https://www.knoll.com (26.01.2017) 